\title{
Adaptive Hysteresis Band Current Control for Transformerless Single-Phase PV Inverters
}

\author{
*Gerardo Vázquez, Pedro Rodriguez \\ Technical University of Catalonia \\ Department of Electrical Engineering \\ Barcelona-SPAIN \\ "gerardo.vazquez@upc.edu
}

*Rafael Ordoñez

Technological Institute of Apizaco

Department of Electronic Engineering

Tlaxcala, México

rafael.ordonezf@gmail.com
*Tamás Kerekes, Remus Teodorescu Aalborg University

Institute of Energy Technology

Aalborg - DENMARK

*tak@iet.aau.dk

\begin{abstract}
Current control based on hysteresis algorithms are widely used in different applications, such as motion control, active filtering or active/reactive power delivery control in distributed generation systems. The hysteresis current control provides to the system a fast and robust dynamic response, and requires a simple implementation in standard digital signal platforms. On the other hand, the main drawback of classical hysteresis current control lies in the fact that the switching frequency is variable, as the hysteresis band is fixed. In this paper a variable band hysteresis control algorithm will be presented. As it will be shown, this variable band permits overcoming the aforementioned problem giving rise to an almost constant switching frequency. The performance of this algorithm, together with classical hysteresis controls and proportional resonant (PR) controllers, has been evaluated in three different single-phase PV inverter topologies, by means of simulations performed with PSIM. In addition, the behavior of the thermal losses when using each control structure in such converters has been studied as well.
\end{abstract}

\section{INTRODUCTION}

The classical current control techniques for power converters, based on PWM modulation, present a certain control delay that does not permit to control accurately the instantaneous-peak of the currents that are being delivered by a power converter [1]. In order to solve this issue, asynchronous sine-triangle PWM voltage control can be used in conjunction with instantaneous current feedback control. However, when this method is used the error signals are nearly sinusoidal and the dynamical response of the system is limited by the stability bandwidth of the feedback loops.

The use of predictive voltage control techniques [2] permits improving the bandwidth of the controller, as the tracking of the reference does not depends exclusively on the controller tuning, but also on the feedforward control signal provided by the predictive algorithm. Although these techniques tend to give optimum performance in terms of response and accuracy, they depend highly on the accuracy of the predictive model and they are somehow complicated to implement in standard Digital Signal Processors (DSP) [3,4].

As an alternative to PWM techniques hysteresis current controllers have been broadly used also, as they can be easily implemented with no complex hardware. Another important advantage of this kind of controllers is its fast dynamic response and their inherent capability to limit the peak current injected by the converter. In addition, hysteresis controllers do not require any information about the system parameters, something that enhances its robustness.
In classical hysteresis controllers the error band is normally fixed to a certain value. As a consequence the switching frequency varies within a band because peak-to-peak current ripple must be controlled at all points of the fundamental frequency wave. In order to solve this problem without damaging the good dynamical performance of the hysteresis current control, an adaptive hysteresis band able to maintain a constant switching frequency is proposed in this paper. In the following the algorithm that has been developed in order to calculate the value of the hysteresis band will be detailed. Later on their performance will be tested in three different power converter topologies used for single phase PV applications. The results obtained with the new algorithm will be compared with those obtained when using classical hysteresis and PR controllers. This analysis will be extended as well to the thermal losses that appear in the power converter in each case.

\section{BASIC HYSTERESIS CURRENT CONTROL}

The basic hysteresis current control is based on an on-line PWM control that fixes the output voltage of the inverter instantaneously [5].

The main task of the PWM current controller in an inverter is to adjust the output current, $i$, in order to track the current reference provided by $i^{*}$. Comparing the instantaneous current in the load with the reference signal the controller should adjust the duty cycle of the PWM signal in the inverter. As a consequence, the error signal ( $\delta$ ) should be reduced [6]. A basic scheme of the PWM current controller is shown in Fig. 1.

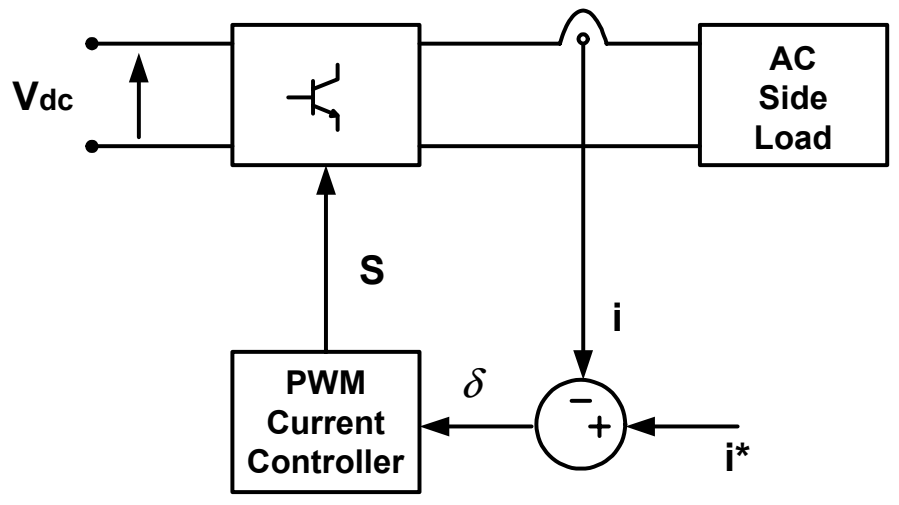

Fig. 1. Basic Current Control Scheme in a single phase inverter. 
In this kind of controller, the output voltage level depends on the error between the current setpoint and the real currents injected by the converter. In this way when the load current is lower than the current reference, the inverter connects the positive side of the DC bus to the load, reducing thus the currents. On the contrary when the load current is higher than the current reference, the inverter connects the negative side of the DC bus to the load. Taking into account the previous description, the error signal can be maintained within a certain fixed band. Fig. 2 shows the evolution of the load current when using a basic hysteresis current control.

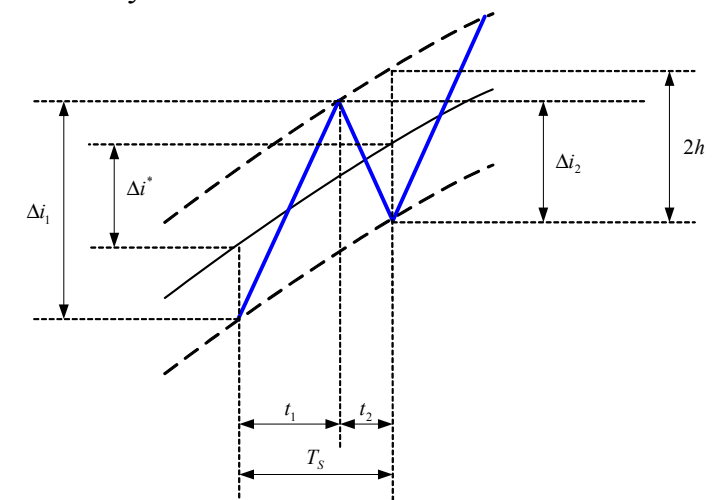

Fig. 2. PV inverter Output current with hysteresis control.

However, and in spite of its good dynamic response, this fixed error band makes the switching frequency vary according to the slope of the reference signal. This variable switching frequency may cause several problems in the system such as: overheating of the converter, difficulty in the filter design, resonances and appearance of nonoptimum current ripple in the load [7].

In order to overcome the aforementioned problems the basic hysteresis current control system can be modified in order to get an almost constant switching frequency. In the following section it will be shown how, it is possible to design an adaptive hysteresis band algorithm for a single phase PV inverter able to keep a constant switching frequency.

\section{Proposed Hysteresis CURRENT CONTROL}

Considering that the output current of the inverter is the one shown in Fig. 2, the error signal can be written as (1):

$$
\delta=i-i^{*}
$$

where $i$ is the output current and $i^{*}$ is the reference current. It is possible to deduct an equation for each switching period written in (2) and (3). According to Fig 2, for $\left[0, \mathrm{t}_{1}\right]$ :

$$
\frac{d \delta}{d t}=\frac{d i}{d t}-\frac{d i^{*}}{d t}=\frac{\Delta i_{1}}{t_{1}}-\frac{\Delta i^{*}}{T_{s}}=\frac{2 h}{t_{1}}
$$

And for $\left[t_{2}, T_{s}\right]$ :

$$
\frac{d \delta}{d t}=-\frac{d i}{d t}-\frac{d i^{*}}{d t}=-\frac{\Delta i_{2}}{t_{2}}-\frac{\Delta i^{*}}{T_{s}}=-\frac{2 h}{t_{2}}
$$

Fig. 3 shows a PV inverter with H5 structure [8]. During the positive semicycle when switches $\mathrm{S} 5, \mathrm{~S} 1$ and $\mathrm{S} 4$ are $\mathrm{ON}$ and $\mathrm{S} 2, \mathrm{~S} 3$ are OFF, an active vector is applied to the load. This switching semiperiod correspond to $t_{1}$ in Fig. 2 when the current is increasing. In order to apply a zero voltage vector to the load, S5 is turn off whereas, S1, S2, S3 and S4 remain in the same state. This switching period correspond to $t_{2}$ in Fig. 2 when the current is decreasing (freewheeling case). The equivalent circuits in both periods are shown in Fig 4.

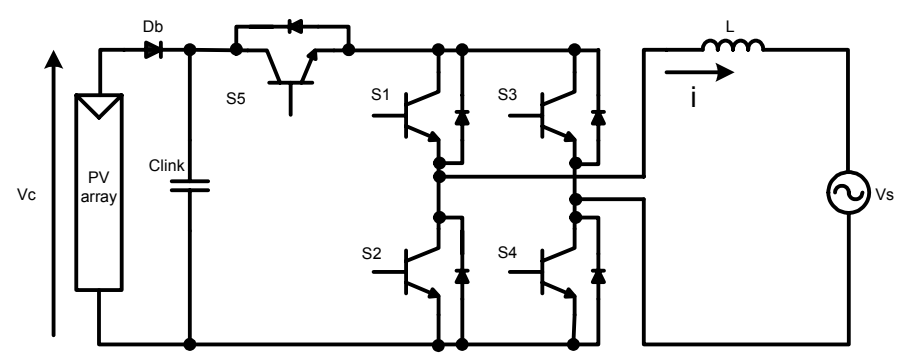

Fig. 3. Basic structure of a H5 PV inverter.
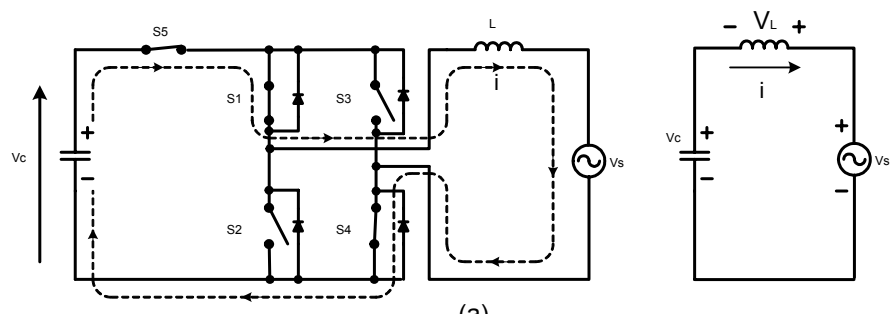

(a)
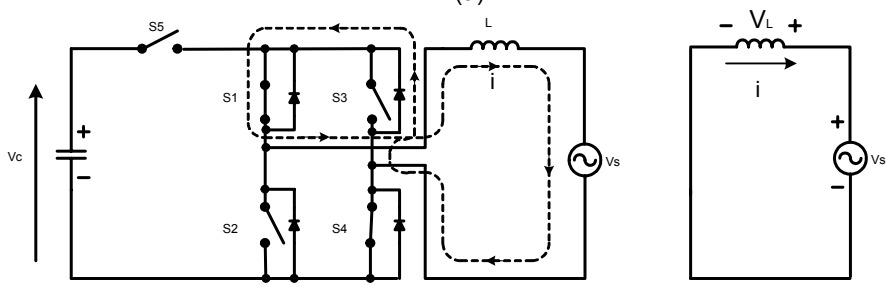

(b)

Fig. 4.Equivalent circuits (a) active voltage vector, (b) zero voltage vector.

According with the equivalent circuits shown in Fig. 4, it is possible to establish the equations for the equivalent circuits in both periods (4) and (5).

$$
\begin{aligned}
& V_{C}-V_{s}=L \cdot\left(\frac{d i^{*}}{d t}+\frac{d \delta}{d t}\right) \\
& 0-V_{s}=L \cdot\left(\frac{d i^{*}}{d t}+\frac{d \delta}{d t}\right)
\end{aligned}
$$

Substituting equations (2) and (3) in equations (4) and (5) respectively it is possible to obtain the following equations: 


$$
\begin{aligned}
& \left(V_{C}-V_{s}-L \frac{d i^{*}}{d t}\right) \cdot t_{1}=2 \cdot L \cdot h \\
& \left(-V_{s}-L \frac{d i^{*}}{d t}\right) \cdot t_{2}=-2 \cdot L \cdot h
\end{aligned}
$$

Adding equations (6) and (7):

$$
t_{1}=\frac{T_{s}}{V_{C}}\left(V_{s}+L \frac{d i^{*}}{d t}\right)
$$

Finally, by means of substituting the equation (8) in equation (6) and simplifying terms equation (9) is reached:

$$
h=\frac{T_{s}}{2 L} \cdot\left(V_{s}+L \frac{d i^{*}}{d t}\right)\left[1-\frac{1}{V_{C}} \cdot\left(V_{s}+L \frac{d i^{*}}{d t}\right)\right]
$$

Equation (9) defines an adaptive hysteresis band that depends on the system parameters. This algorithm permits to obtain a constant switching frequency in the PV inverter load. The same analysis can be performed for other topologies like HERIC (High Efficiency Reliable Inverter Concept) [9], shown in Fig. 5, or HB-ZVR (Half-Bridge Zero Voltage Rectifier) [10], depicted in Fig. 6.

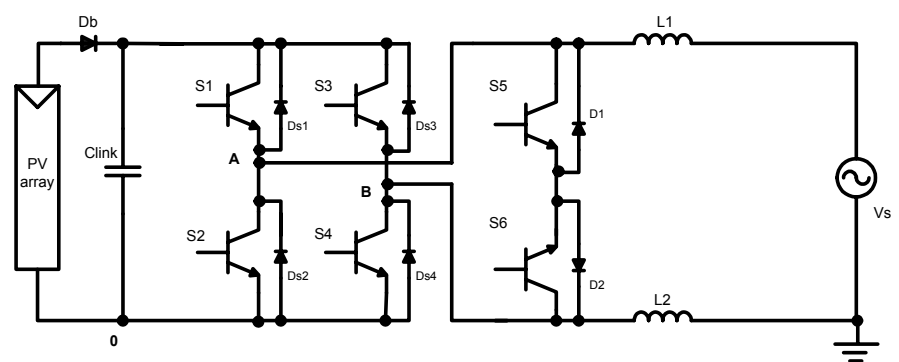

Fig. 5. High Efficient and Reliable Inverter Concept (HERIC) topology.

In the HERIC topology during the positive half cycle S6 remains connected, whereas S1 and S4 commutate at switching frequency in order to generate both active and zero vectors. When an active vector is present ( $\mathrm{S} 1$ and $\mathrm{S} 4$ are $\mathrm{ON}$ ), current flows from the PV panels to the load (grid), when a zero vector occurs, S1 and S4 are switched OFF and then, the current flows through S6 and D1, this is the freewheeling situation. On the other hand, when the negative cycle is coming, S6 goes OFF and S5 goes ON, whereas S3 and S2 commutate at switching frequency. This means that an active vector is present when S3 and $\mathrm{S} 2$ are ON, therefore the current flows from the PV panel towards the load, thus when S3 and S2 turn off, a zero voltage vector is present in the load, then current flows through S5 and D2. This kind of modulation permits having a freewheeling situation with no connected load (utility grid).

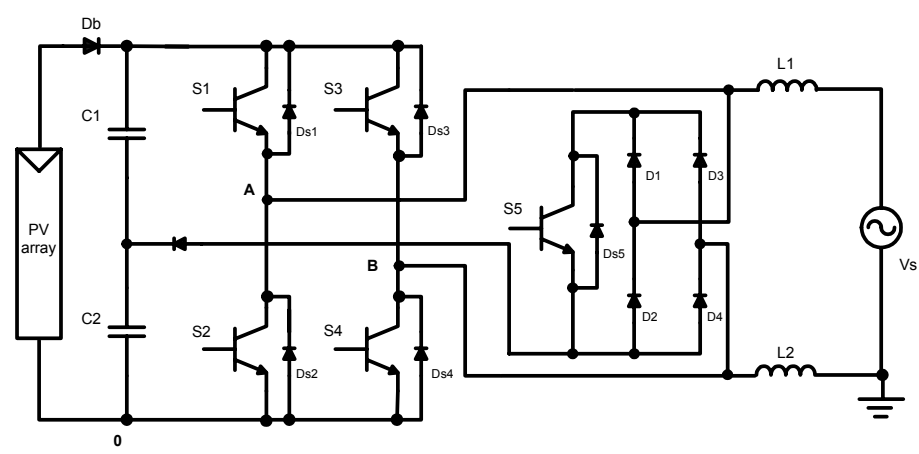

Fig. 6. Half-Bridge Zero Voltage Rectifier (HB-ZVR) topology.

In turn the HB-ZVR topology, Fig. 6, it provides the active vectors using a conventional full-bridge inverter, whereas the zero voltage vectors are generated by the single phase rectifier and S5. This topology works as follow: during positive semicycle, when an active vector is applied, switches S1 and S4 are $\mathrm{ON}$, and $\mathrm{S} 2, \mathrm{~S} 3$ and $\mathrm{S} 5$ are OFF, in this situation the output current is increasing. In order to apply a zero voltage vector, S1 and S4 are turn off and S5 is turn on, in this case, the current is decreasing. On the other hand, in the negative semi-cycle, an active vector is applied when S2 and S3 are ON, and S1, S4 and $\mathrm{S} 5$ are $\mathrm{OFF}$, whereas a zero voltage vector is applied when $\mathrm{S} 1, \mathrm{~S} 2, \mathrm{~S} 3$ and $\mathrm{S} 4$ are OFF and S5 is ON.

In the next section, simulations results using hysteresis current control were performed in order to compare the system performance with and without adaptive hysteresis band.

All simulations were performed using PSIM (Thermal Module). The IGBT is an IPM (Intelligent Power Module) from Mitsubishi PM75DSA120. In this study case the DC bus was of $400 \mathrm{~V}$, while the load was a grid with $L=4 \mathrm{mH}, V s=$ $325 V_{p k}$ and $f=50 \mathrm{~Hz}$.

\section{Simulation Results}

In this section simulations with H5, HERIC and HB-ZVR topologies have been carried out. The simulation results using the adaptive band hysteresis algorithm in the H5, HERIC and ZB-ZVR topologies are shown in Fig. 7, Fig. 8 and Fig. 9 respectively.

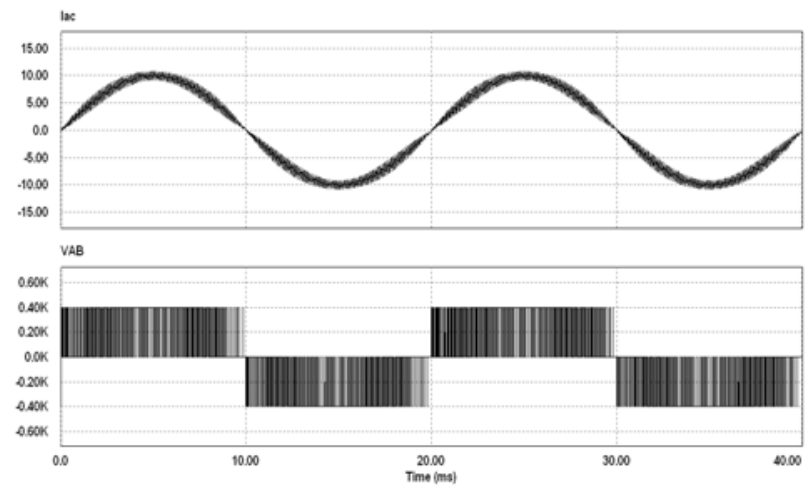

Fig. 7. Behavior of the current and the voltage at the output of the converter when using the H5 topology. 


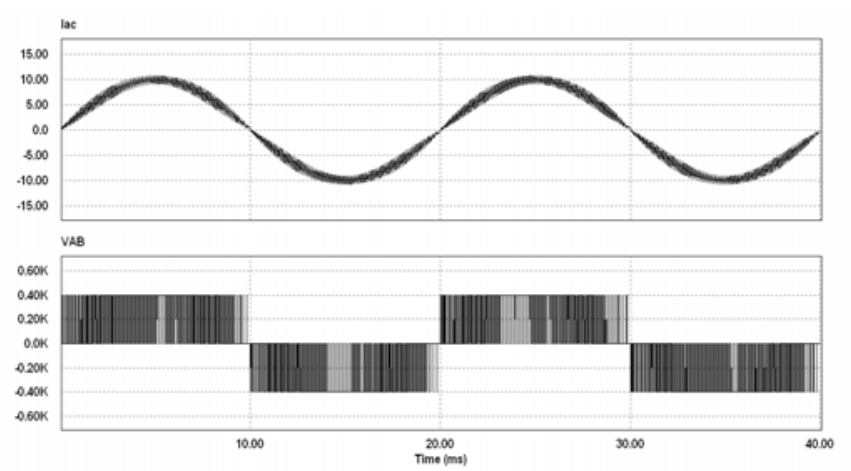

Fig. 8. Behavior of the current and the voltage at the output of the converter when using the HERIC topology.

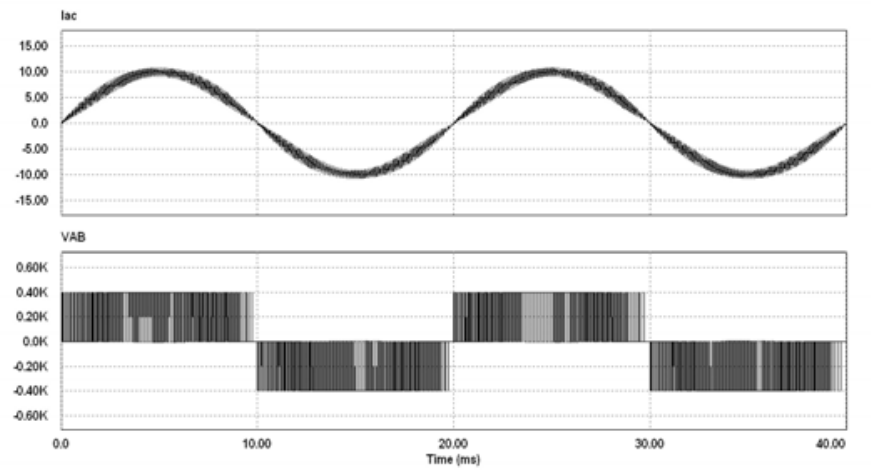

Fig. 9. Behavior of the current and the voltage at the output of the converter when using the or HB-ZVR topology.

In order to see that the switching frequency is almost constant in all three cases, it is necessary to obtain the output current harmonic spectrum. Fig. 10 shows the harmonic spectrum for the HERIC topology with and without adaptive hysteresis band. In the other two cases (H5 and HB-ZVR), the current spectrum is almost the same.
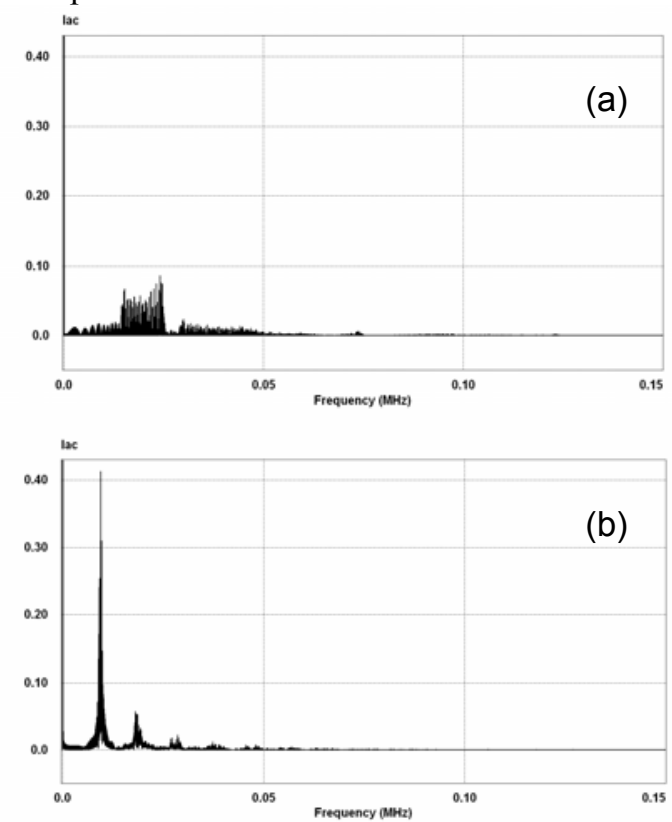

Fig. 10. Frequency spectrum of the output current for HERIC topology, (a) Without adaptive hysteresis, (b) With adaptive hysteresis.
As can be seen in Fig. 10, in case (a) the switching frequency is variable over a wide frequency range and in the case (b) the switching frequency remains around $10 \mathrm{kHz}$. This characteristic permits to design easily the output filter of the inverter.

In the next section it is presented some simulations results regarding switching and conduction losses for these three topologies. The IGBT model used in these simulations was obtained by means IGBT datasheet and after that, was loaded to PSIM library.

\section{COMPARATIVE LOSSES ANALYSIS}

In order to obtain good comparative losses analysis, all three topologies were simulated with a fixed hysteresis band current control (Basic $\mathrm{H})$, adaptive hysteresis band current control (Adaptive $\mathrm{H}$ ) and proportional resonant current control (PR Ctrl). Table 1 shows the simulation results of total switching and conduction losses with an input power of $1650 \mathrm{~W}$ $\left(\mathrm{I}_{\text {out }}=10 \mathrm{Amp}\right)$ for all three topologies.

TABLE 1

SWITCHING AND CONDUCTION LOSSES

\begin{tabular}{|c|c|c|l|}
\hline \multirow{3}{*}{ Topology } & \multicolumn{2}{|c|}{$P_{\text {in }}=1650 \mathrm{~W} / I_{\text {out }}=10 \mathrm{Amp}$} & \multirow{2}{*}{ Control } \\
\cline { 2 - 4 } & $\begin{array}{c}\text { Switching } \\
\text { Losses (W) }\end{array}$ & $\begin{array}{c}\text { Conduction } \\
\text { Losses (W) }\end{array}$ & \\
\hline \multirow{3}{*}{ HERIC } & 47.40 & 13.74 & Basic H \\
\cline { 2 - 4 } & 23.54 & 12.76 & Adaptive H \\
\cline { 2 - 4 } & 25 & 12.81 & PR Ctrl. \\
\hline \multirow{3}{*}{ H5 } & 26.16 & 18.08 & Basic H \\
\cline { 2 - 4 } & 12.01 & 18.85 & Adaptive H \\
\hline \multirow{3}{*}{ HB-ZVR } & 13.09 & 18.05 & PR Ctrl. \\
\cline { 2 - 4 } & 89.02 & 15.16 & Basic H \\
\cline { 2 - 4 } & 46.69 & 15.1 & Adaptive H \\
\hline
\end{tabular}

As can be seen in Table 1, the major losses come from IGBT switching processes. This means that the switching frequency has an important influence in the total losses of the system. Due this, when the control is implemented with a fixed hysteresis band, the losses are major than when an adaptive hysteresis band current control system is used.

As shown in Fig. 10 (a), different frequency harmonics appear over a grid period, this harmonics produce an increase of switching losses. Table 1 shows also, that conduction losses are almost the same in each case.

In Table 2 are summarized the distributed losses among all semiconductors in each topology. It is possible to distinguish that the major losses are located in those semiconductors which are switching at high frequency. In addition it is possible to see the specific losses for each semiconductor; with this information, it is possible to perform a good thermal design. 
TABLE 2

DISTRIBUTION LOSSES FOR ALL THREE TOPOLOGIES

\begin{tabular}{|c|c|c|c|c|c|c|c|c|c|c|c|c|c|}
\hline \multirow{2}{*}{ Topology } & \multicolumn{11}{|c|}{ Semiconductor $/ P_{\text {in }}=1650 \mathrm{~W} / I_{\text {out }}=10 \mathrm{Amp}$} & \multirow{2}{*}{$\begin{array}{l}\text { Total } \\
\text { Losses }\end{array}$} & \multirow[t]{2}{*}{ Hysteresis } \\
\hline & S1 & S2 & S3 & S4 & S5 & S6 & D1 & D2 & D3 & D4 & D5 & & \\
\hline \multirow{3}{*}{ HERIC } & 13.20 & 13.26 & 13.20 & \begin{tabular}{|l|l|}
13.26 \\
\end{tabular} & 1.09 & 1.09 & 2.99 & \begin{tabular}{|l|}
2.99 \\
\end{tabular} & ***** & **** & $* * *$ & 61.14 & Basic \\
\hline & \begin{tabular}{|l|}
7.49 \\
\end{tabular} & 7.51 & 7.49 & 7.51 & 1.12 & 1.12 & 2.01 & 2.01 & ${ }^{* * * * *}$ & ***** & $k^{* * * * *}$ & 36.31 & Adaptive \\
\hline & 7.83 & 7.85 & 7.83 & 7.85 & 1.12 & 1.12 & 2.09 & 2.09 & ${ }^{* * * * *}$ & $* * *$ & $* * *$ & 37.82 & PR Ctrl. \\
\hline \multirow{3}{*}{ H5 } & 3.45 & 3.45 & 3.45 & 3.45 & 15.21 & 15.22 & $* * *$ & **** & $* * *$ & $* * * *$ & ${ }^{* * * *}$ & 44.25 & Basic \\
\hline & 3.11 & 3.12 & 3.1 & 3.1 & 9.21 & 9.21 & $* * * *$ & $* * *$ & $*^{* * * * *}$ & $* * *$ & $* * *$ & 30.86 & Adaptive \\
\hline & 3.21 & 3.17 & 3.28 & 3.3 & 9.09 & 9.09 & $*^{* * * *}$ & **** & $*^{* * * *}$ & $* * *$ & $* * *$ & 31.15 & PR Ctrl. \\
\hline \multirow{3}{*}{ HB-ZVR } & 12.35 & 12.38 & 12.36 & \begin{tabular}{|l|l|}
12.38 \\
\end{tabular} & $\begin{array}{ll}42.80 \\
\end{array}$ & "**** & 2.97 & 2.97 & 2.97 & 2.97 & 0 & $\begin{array}{l}104.19 \\
\end{array}$ & $\begin{array}{l}\text { Basic } \\
\end{array}$ \\
\hline & 7.51 & 7.53 & 7.52 & 7.53 & 23.68 & $* * * *$ & 2.01 & 2.01 & 2.01 & 2.01 & 0 & 61.86 & Adaptive \\
\hline & 7.83 & 7.84 & 7.83 & 7.85 & 24.98 & ***** & 2.08 & 2.08 & 2.08 & 2.08 & 0 & $\begin{array}{ll}64.7 \\
\end{array}$ & PR Ctrl. \\
\hline
\end{tabular}

In the case of H5 topology, the losses are located in S5. In all three cases the losses behavior is almost the same, the losses are reduced when adaptive hysteresis band current control and proportional resonant current control are used.

The efficiency in each topology was obtained taking into account the semiconductor losses. The Fig. 11 shows the results with fixed hysteresis band current control, adaptive hysteresis band current control and proportional resonant current control.

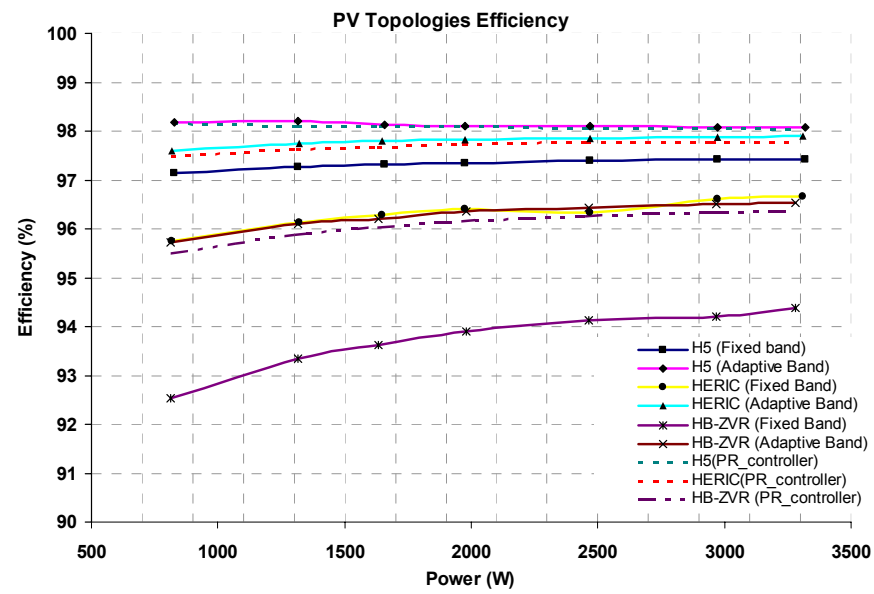

Fig. 11. PV topologies efficiency using fixed hysteresis band, adaptive hysteresis band and proportional resonant current controllers.

As can be seen in Fig. 11, the efficiency in each topology when an adaptive hysteresis current control is used is a bit better than when a proportional resonant current control is used.

\section{CONCLUSIONS}

A hysteresis current control algorithm based on an adaptive hysteresis band for single phase PV converter topologies has been presented in this paper. As it has been shown analytically and by means of simulations this algorithm permits obtaining a fixed switching frequency in all the tested topologies.

The main drawback of the conventional fixed hysteresis band current control is that generates excessive current ripple because modulation frequency varies within a band. This modulation frequency variation makes complicated the output filter design. Adaptive hysteresis band current control keeps the good performance of the fixed band hysteresis current control and additionally permits an easier output filter design due that the switching frequency is almost constant. On the other hand, switching losses can be reduced by using this adaptive hysteresis band current control.

The analyzed topologies are the more widely used in transformerless single-phase PV systems (H5 and HERIC). Based in the previously comparative simulations results it can be concluded that in the case of H5 topology losses are concentrated in S5. In case of HERIC topology losses are located among S1, S2, S3 and S4. Finally in HB-ZVR single phase topology, losses are located in S5. These results mean that in each case, the losses distribution is not the same and a different thermal design should be done.

\section{ACKNOWLEDGMENT}

This research work was supported by the project ENE20080841-C02-01/ALT from the Spanish Ministry of Science and Technology (MCYT).

\section{REFERENCES}

[1] L. Malesani, P. Mattavelli, P. Tomasin, "High Performance Hysteresis Modulation Technique for Active Filters", IEEE Transactions on Power Electronics, Volume 12, September 1997.

[2] J. Holtz and S. Stadtfeld, "A Predictive Controller for the Stator Current Vector of AC Machine-fed from a Switched Voltage Source", in Proc. Int. Power Electronics Conference Rec. (Tokyo), 1983, pp. 1665-1675.

[3] M. Ciobotaru, R. Teodorescu, and F. Blaabjerg, "Control of Single-Stage Single-Phase PV Inverter", European Conference on Power Electonics and Applications, 2005.

[4] Y. Hayashi, N. Sato, K. Takahashi, "A Novel Control of a CurrentSource Active Filter for ac Power System Harmonic Compensation", IEEE Transactions on Industrial Applications, Vol. 27, No. 2, March/April 1991.

[5] T. Kato, K. Miyao, "Modified Hysteresis Control with Minor Loops for Single-Phase Full-Bridge Inverters", Doshisha University, Kyoto Japan, 88CH2565-0/88/0000-0689\$01.00, 1988 IEEE.

[6] Bimal K. Bose, "An Adaptive Hysteresis- Band Current Control Technique of a Voltage-Fed PWM Inverter for Machine Drive System", IEEE Transactions on Idustrial Electronics, Vol. 37, No 5, October 1990.

[7] Marian P. Kazmierkowski, Luiguui Malesani, "Current Control Techniques for Three-Phase Voltage-Source Converters: A Survey", IEEE Transactions on Industrial Electronics, Vol. 45, No. 5, October 1998.

[8] EP 1626494 A2; Europeische Patentanmeldung, European Patent Office

[9] EP 1369985 A2; Europeische Patentanmeldung, European Patent Office

[10] T. Kerekes, G. Vazquez, P. Rodriguez, E. Aldabas, R. Teodorescu, "A New High-Efficiency Single-Phase Transformerless PV Inverter Topology", IEEE Transactions on Idustrial Electronics, 2009 